\title{
ARTICLE OPEN \\ The controlling role of sodium and carbonate on the atmospheric corrosion rate of aluminum
}

\author{
Rebecca F. Schaller ${ }^{1}$, Carlos F. Jove-Colon ${ }^{2}$, Jason M. Taylor ${ }^{1}$ and Eric J. Schindelholz ${ }^{1}$
}

\begin{abstract}
Aluminum and aluminum alloys are widely used in many outdoor applications due to their inherent corrosion resistance attributed to the formation of a protective oxide layer. While corrosion rates are generally considered low for aluminum in many atmospheric environments, understanding of the corrosion performance over time is necessary to predict the cost, safety, and esthetics of these materials. The vast majority of the knowledgebase of atmospheric aluminum corrosion is built on environment-response relationships; often based on statistical correlation of corrosion rate data with atmospheric environmental conditions. However, there is still a limited mechanistic understanding of corrosion processes associated with this linkage. This lack in knowledge prevents interpretation and limits the extrapolation of these statistical datasets for prediction purposes. Here, the mechanistic dependence of aluminum corrosion rate on salt loading is explored through complimentary experimental and theoretical analysis relating corrosion rate to electrolyte chemistry, volume and corrosion products. From these results a reaction pathway is proposed for the atmospheric corrosion of aluminum that accounts for the governing effects of $\mathrm{CO}_{2}$ and salt loading on corrosion rate. This reaction pathway provides a new perspective that highlights the importance of the formation and growth of dawsonite $\left(\mathrm{NaAlCO}_{3}(\mathrm{OH})_{2}\right)$, and the subsequent gettering of sodium from the electrolyte leading to the stifling of corrosion kinetics. This study highlights the importance of accounting for the dynamic physical and chemical state of the electrolyte during corrosion in process models and measurement techniques to better understand and predict atmospheric corrosion behavior.
\end{abstract}

npj Materials Degradation (2017)1:20; doi:10.1038/s41529-017-0020-3

\section{INTRODUCTION}

A general observation of atmospheric corrosion of metals in both field and laboratory environments is that corrosion rate increases with salt loading in saline conditions. ${ }^{1-18}$ Statistical models relate corrosion, in terms of mass loss or gain, to environmental parameters, such as relative humidity $(\mathrm{RH})$ and chloride deposition rate, and show chloride deposition to have a positive contribution to the corrosion rate. ${ }^{12,19}$ In field environments these correlations, however, are convoluted by a multiplicity of environmental parameters with little direct insight into the underlying mechanistic linkage between salt load and corrosion rate.

Theoretical analyses and laboratory studies under rigorously controlled conditions have demonstrated the governance of electrolyte volume and geometry, and, circumstantially, soluble salt load, on atmospheric corrosion kinetics. Salt, such as sodium chloride, imparts electrolyte to the surface through water uptake from the air, primarily via deliquescence (solid-aqueous) phase transitions. In this manner, salt load can control available anode-cathode area through electrolyte coverage and corrosion cell efficiency (volume and geometry); higher salt loads generally increase coverage and volume and tend towards thin, continuous films. Factors affecting efficiency include electrolyte resistance, which can reduce the effective cathode area, ${ }^{20,21}$ along with the electrolyte path length for oxygen to reach the surface when oxygen reduction is the rate limiting step. ${ }^{22,23}$ While the individual relationships of these factors with electrolyte geometry are generally understood under ideal conditions at the initial stage of corrosion, less is known regarding their combined influence or competition experienced as corrosion advances.

Once corrosion initiates under salt deposits, local physicochemical conditions, such as $\mathrm{pH}$ and ionic strength, rapidly evolve, in turn affecting the kinetic mechanisms governing corrosion. Chemical gradients are established through anode-cathode distribution and interaction with the atmosphere. Hydrolysis at the anode can acidify regions, whereas cathodic activity associated with the spreading of catholyte can establish and expand alkaline regions beyond original salt deposits. ${ }^{24}$ In the case of aluminum, it has been hypothesized that $\mathrm{CO}_{2}$ can neutralize these $\mathrm{pH}$ gradients, thus reducing the strong anode/ cathode development. ${ }^{25}$ The production of corrosion products can also affect kinetics as they can become physical barriers to ionic transport. ${ }^{26}$ Changes in the surface passive state may reduce or enhance the corrosion kinetics. The basics of the corrosion pathway process on aluminum have been previously established. ${ }^{13,25,27,28}$ Specific to atmospheric corrosion, Le Bozec et al. have proposed an auto-catalytic corrosion pathway in which initial anodic dissolution occurs, cations migrate towards the cathode as $\mathrm{OH}^{-}$is produced and a $\mathrm{pH}$ gradient is established. At the cathode, the cations are incorporated into the aluminum hydroxide gel as $\mathrm{Cl}^{-}$ions are released and migrate back towards the anode. ${ }^{13}$ However, this does not provide an explanation for the stifling of $\mathrm{Al}$ corrosion or specifically address the presence of dawsonite $\left(\mathrm{NaAlCO}_{3}(\mathrm{OH})_{2}\right)$ observed under constant atmospheric exposures. ${ }^{25,29}$

\footnotetext{
${ }^{1}$ Center for Materials Science and Engineering, Sandia National Laboratories, PO Box 5800, Albuquerque, NM 87185, USA and ${ }^{2}$ Geosciences Engineering, Sandia National Laboratories, PO Box 5800, Albuquerque, NM 87185, USA

Correspondence: Eric J. Schindelholz (ejschi@sandia.gov)
}

Received: 20 June 2017 Revised: 28 September 2017 Accepted: 17 October 2017

Published online: 14 November 2017 
a

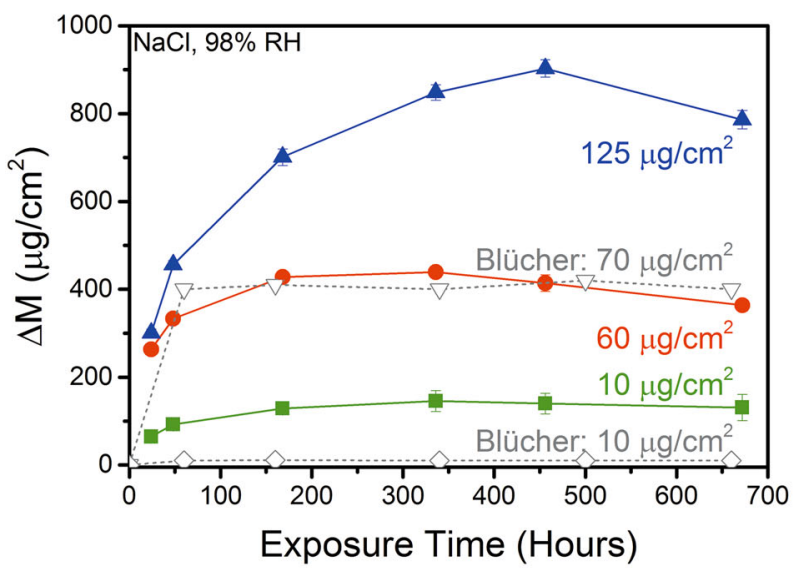

b

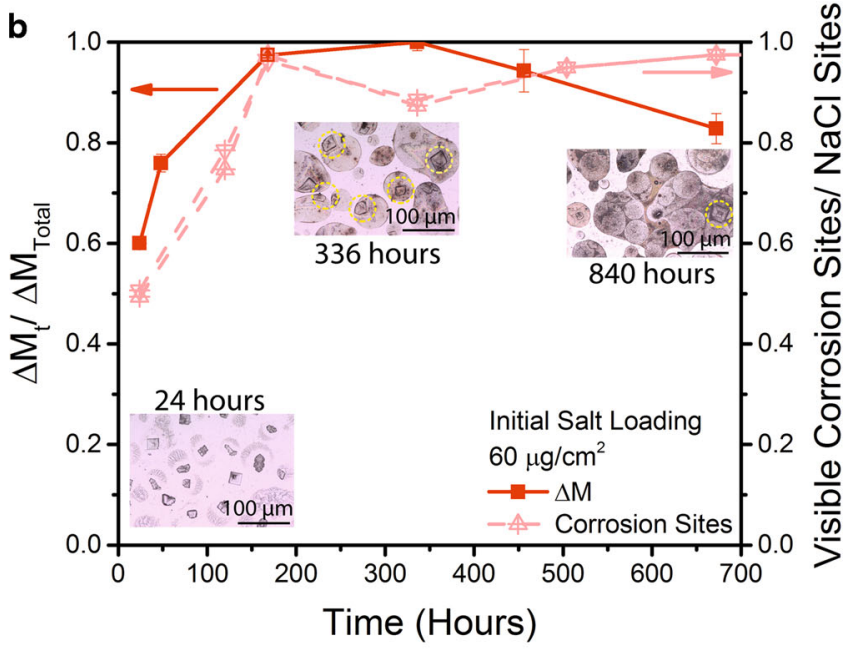

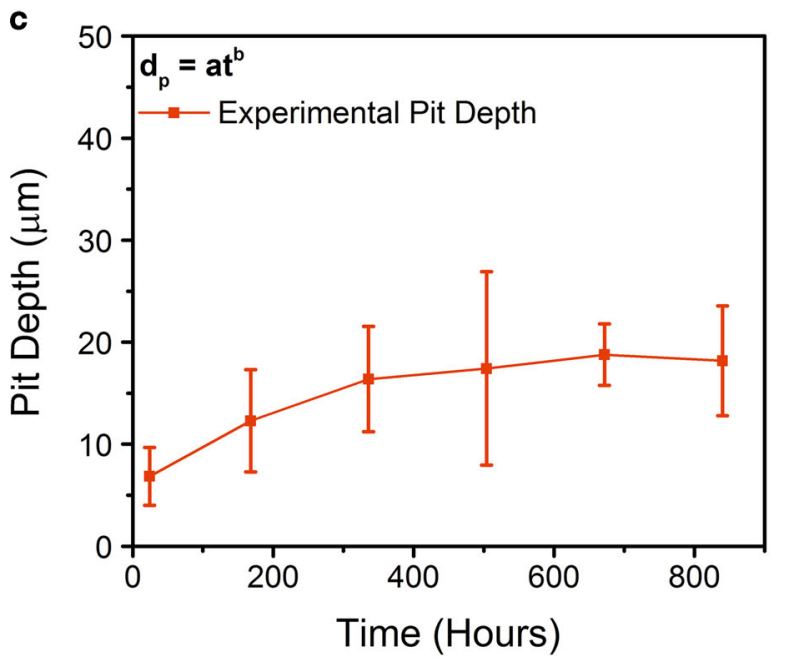

Fig. 1 a Average mass gain vs. exposure time at $98 \% \mathrm{RH}, 21^{\circ} \mathrm{C}$ for Al 1100 with 10,60 , and $125 \mu \mathrm{g} / \mathrm{cm}^{2} \mathrm{NaCl}$ compared to results from Blucher et al. ${ }^{1}$ b Ratio of salt particles that exhibited visible corrosion to the initial salt particle density compared to the normalized mass loss for samples with $60 \mu \mathrm{g} / \mathrm{cm}^{2}$, optical images of $\mathrm{NaCl}$ post-exposure inset. Remaining $\mathrm{NaCl}$ particles outlined in yellow. c Measured maximum pit depth from SWLI vs. time for samples exposed with $60 \mu \mathrm{g} / \mathrm{cm}^{2}$. Error bars represent one standard deviation in measurement

In this study, the relationship between the dynamic physicochemical state of electrolyte and corrosion rate under a range of fixed salt loadings as corrosion progresses for up to 30 days was examined. The focus is on the specific case of sodium chloride on aluminum in high humidity conditions, wherein previous investigators have reported stifling of corrosion after only several days exposure. ${ }^{25}$ Here it is proposed that stifling is a result of gettering of sodium by corrosion products, effectively leading to drying of the electrolyte on the surface and reduction of the cathode area. The results presented here are in support of this premise through time-resolved gravimetric measurements of $\mathrm{NaCl}$ loaded aluminum (UNS A91100) coupons along with characterization and complimentary theoretical analysis of electrolyte chemistry, volume, and corrosion products.

\section{RESULTS}

Aluminum coupons exposed at $98 \% \mathrm{RH}$ and $21^{\circ} \mathrm{C}$ with initial salt loading densities of 10,60 , and $125 \mu \mathrm{g} / \mathrm{cm}^{2}$ exhibited mass gain measurements that are consistent with previous studies (Fig. 1a). ${ }^{25}$ The extent of corrosion or mass gain corresponded to salt loading; mass gain increased monotonically with initial salt loading (Fig. 1a). Mass gain rate is observed to significantly stifle (to below the detection limit of the balance used) over time, with the bend over in mass gain rate for lower loadings occurring at shorter time spans (Fig. 1a). At long times, for the higher salt loadings, the mass gain appeared to decrease slightly below the maximum, which may be due to small losses of corrosion product during measurement. However, this does not affect the general bend over trend observed, as all samples, across all exposures, exhibited this same stifling trend. The normalized mass gain (mass gain at time, $t$, divided by the maximum mass gain) is plotted with the visible corrosion sites (the salt droplets exhibiting corrosion/ total initial number of salt droplets per area) in Fig. 1b. Through optical imaging of the salt deposits during exposure it is apparent that not all salt particles (droplets) initiated corrosion at the same time and even after $840 \mathrm{~h}$ ( 35 days) of exposure, some $\mathrm{NaCl}$ particles were still present on the surface (Fig. 1b, circled in yellow). Electrolyte was observed to be in the form of droplets for all loadings and time rather than strictly thin films. Post exposure, dawsonite $\left(\mathrm{NaAlCO}_{3}(\mathrm{OH})_{2}\right)$ was the only corrosion product identifiable on these coupons through grazing incidence $X$-ray diffraction (GIXRD). Post exposure and after corrosion product removal, maximum pit depths were measured using scanning white light interferometry (SWLI), indicating a bend over, or stifling in the pit depth with exposure time, Fig. 1c. 
a

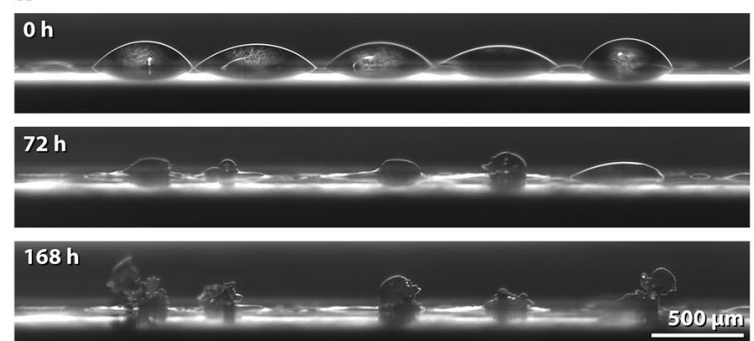

b

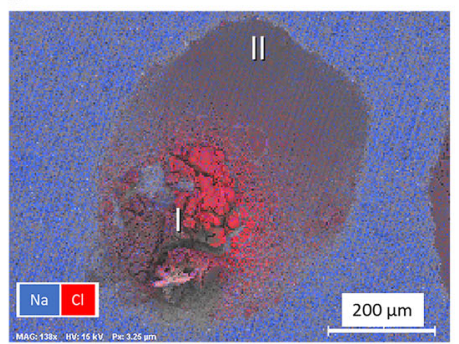

C

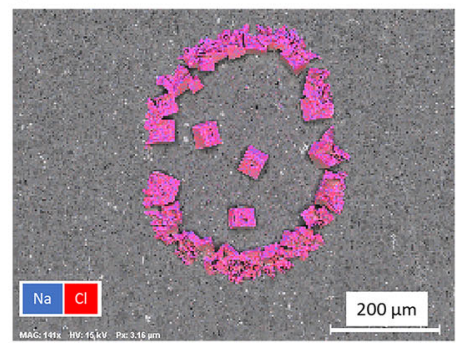

Fig. 2 a Images in situ of $\mathrm{NaCl}$ droplet exposure over time, at $98 \% \mathrm{RH}$ and $21^{\circ} \mathrm{C}$. SEM/EDS composite image of $\mathrm{Na}$ and $\mathrm{Cl}$ distribution across an b exposed droplet where I is the near pit region and II is the droplet edge region and $\mathbf{c}$ an unexposed droplet

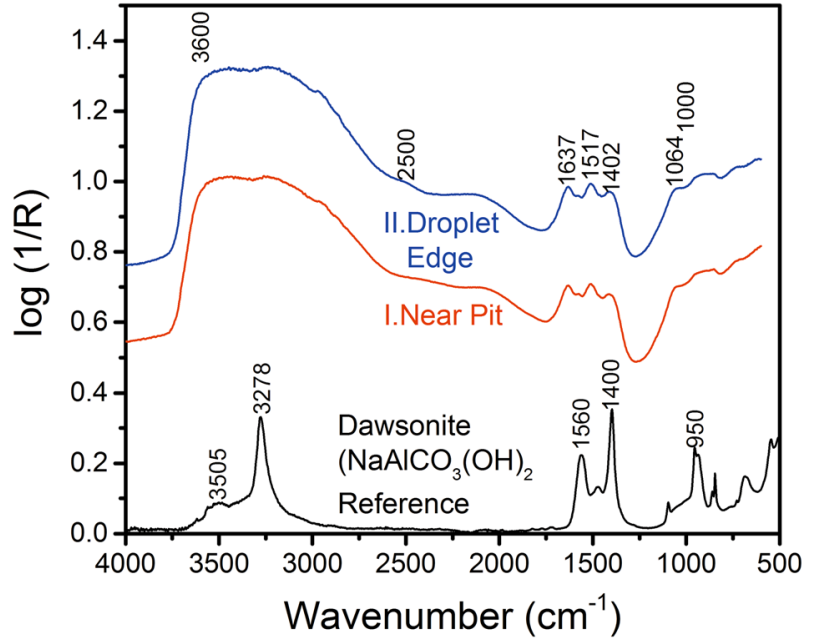

Fig. 3 FTIR spectra of droplet edge and near pit regions of an $\mathrm{NaCl}$ singular droplet post-exposure at $98 \% \mathrm{RH}$ and $21^{\circ} \mathrm{C}$ compared to a dawsonite reference spectra, as well as important peaks noted

Complimentary experiments were carried out in the same conditions whereby in situ time lapse imaging was performed on arrays of singular $\mathrm{NaCl}$ droplets (minimum of ten droplets per array, of which five were imaged) on aluminum, Fig. 2a. Even near saturated humidity conditions $(98 \% \mathrm{RH})$ and well above the $\mathrm{NaCl}$ deliquescence point $(75 \% \mathrm{RH})$, electrolyte volume decreased with time as corrosion product grew during the exposure. Micro droplets formed near original droplets within 5-10 min after loading of droplets on the sample surface and exposure at high relative humidity (98\%). Also, a large spreading zone (diameter $>4000 \mu \mathrm{m}$ ) was observed through optical imaging post-exposure, indicating droplet spreading. These spreading zones were found to be $\mathrm{Na}$ rich and $\mathrm{Cl}$ deficient, with the bulk of the $\mathrm{Cl}$ found collocated with the corrosion product, Fig. 2b. This is in stark contrast to a droplet placed on aluminum and then immediately dried, where $\mathrm{Na}$ and $\mathrm{Cl}$ are fully collocated, Fig. 2c. Removal of the corrosion product after exposure revealed pitting attack occurred underneath the buildup of corrosion product. The maximum pit depth measured using SWLI was $50 \mu \mathrm{m}$.

Fourier transform infrared spectroscopy (FTIR) and Raman spectroscopy analysis of corrosion product after exposure of the singular droplet samples indicate corrosion product was primarily composed of dawsonite $\left(\mathrm{NaAlCO}_{3}(\mathrm{OH})_{2}\right)$ along with minor amounts of aluminum hydroxyl carbonates. In both the droplet edge and near pit regions (locations I and II in Fig. $2 \mathrm{~b}$ and respective spectra in Fig. 3), FTIR spectra displayed: dawsonite in the variation in band location $1600-1300,{ }^{30,31}$ evidence of $\mathrm{H}_{2} \mathrm{O}$ or $\mathrm{Cl}^{-}$association in the broad hydroxyl stretch from 3700 to $3200,{ }^{26,32}$ suggestion of carbonate due to the peaks at 1517 and
1402 , and combined with the water and the broad band below 1000 , the suggested presence of $\mathrm{Al}-\mathrm{OH}$-carbonate gel (aluminum hydroxyl carbonate). ${ }^{26}$ The signal from the droplet spreading zone was too weak to obtain significant spectra in the configuration used as the corrosion product buildup would be expected to be very thin in this region. Through Raman spectroscopy (not shown) neither dawsonite nor any other additional corrosion compounds exhibited significantly resolvable peaks.

\section{DISCUSSION}

These results demonstrate a strong relationship between stifling of corrosion rate, electrolyte depletion, and simultaneous formation of corrosion products capable of causing drying. The following discussion outlines how formation of the dominant corrosion product, sodium aluminum carbonate $\left(\mathrm{NaAlCO}_{3}(\mathrm{OH})_{2}\right)$, can lead to electrolyte drying and how, in turn, it can cause corrosion stifling. Based on the following analysis a new mechanism is proposed for atmospheric corrosion of aluminum that importantly accounts for the governing effects of $\mathrm{CO}_{2}$ and salt loading on corrosion rate.

Comparison of electrolyte volume shrinkage with mass gain trends over time indicate that electrolyte volume depletion due to corrosion strongly stifles the average corrosion rate. As corrosion product grows and accumulates across the sample surface, visible electrolyte decreases, and is replaced primarily by sodium aluminum carbonate (Figs. 2a, 3). In situ imaging of corrosion product growth and electrolyte drying can be correlated to the time of stifling observed in the mass gain exposures; when a bend over in the mass gain vs. time occurs in Fig. 1a, between 72 and $120 \mathrm{~h}$, electrolyte is no longer visibly present in Fig. 2a, about 72-96 h.

Average corrosion rates observed in this study follow a power law distribution with considerably higher deceleration in corrosion rate compared to aluminum in immersed saline and atmospheric field exposure conditions, likely reflective of electrolyte limitations due to finite salt loading. Fitting the data in Fig. 4a (dotted line) of maximum pit depth, $d_{\mathrm{p}}$, as function of time, $t$, to:

$d_{\mathrm{p}}=a t^{b}$

results in an $a=0.25 \pm 0.01$ and $b=0.29 \pm 0.01$. These values are comparable to trends from power law fits for immersed and atmospheric conditions of Al 1100 reported elsewhere. ${ }^{33-35}$ Observations of coupon-level and individual droplet experiments suggest the average corrosion rate trends may be collectively dependent on initiation, growth, and stifling of pits associated with drying of individual salt deposits. The fraction of salt deposit sites over time where corrosion is observed to occur; Fig. 1a indicates visibly detectable corrosion activating under different deposits at different times. Assuming that, after initiation under a deposit, each pit or assemblage of pits grows and then stifles due to electrolyte loss, one could expect that a summation of these 

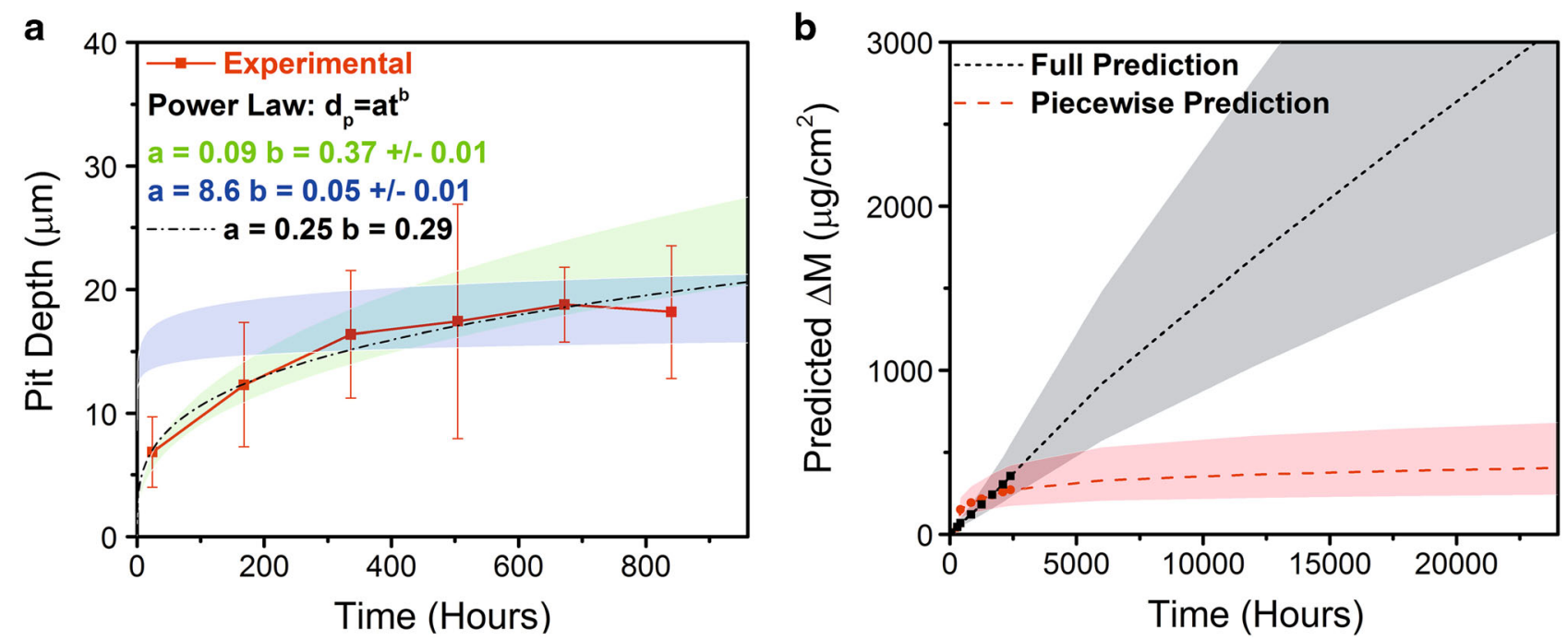

Fig. 4 a Measured maximum pit depth (red) compared to predictions for the power law growth model (black dotted line) and the proposed piecewise fit (blue and green shaded regions) for pitting (Eq. 1) and b predicted mass loss from Eq. 2 (black) compared to the prediction from the piecewise fit of both modes (red). Calculations based on fits to data from Fig. $1 \mathrm{~b}$, c for corroding droplet ratio and pit depth are represented as dots (red and black) while the dashed lines show projected predictions at longer times. Error bars represent one standard deviation in measurement

events would lead to an average corrosion rate across the substrate that is asymptotic to zero. In Fig. $4 \mathrm{~b}$, the estimated mass loss $(\Delta m)$ is calculated assuming hemispherical pit volumes ${ }^{33}$ with pit depths from Eq. 1, the number of corroding sites, $n_{j, t}$ at $t$, the time of exposure from 0 to $l$, the total exposure time, and $j$, the growth time of the individual corrosion sites, from 0 to $k$, the total growth time of each site (from Fig. 1b), and the density, $\rho$, of Al $\left(2.7 \mathrm{~g} / \mathrm{cm}^{3}\right)$ :

$$
\Delta m=\sum_{n_{j=0, t=0}}^{n_{j=k, t=1}} n_{j, t} * \frac{2}{3} \pi\left(0.25 j^{0.29}\right)^{3} * \rho
$$

Using Eq. 2 with the factors for the power law fit for Eq. 1, the predicted mass loss trend due to pitting does not display a bend over or stifling of the corrosion rate (Fig. $4 b$, full prediction in black). If instead, a piecewise fit for the two modes is made, for the initial increasing pit depth and the longer time, stifled pit depth, then the following parameters can be applied; at shorter times, $(t$ $<10$ days) $a=0.09 \pm 0.01$ and $b=0.36 \pm 0.01$ (Fig. 4a, green fit), and at longer times ( $t \geq 10$ days) $a=8.6 \pm 0.01$ and $b=0.05 \pm 0.01$ (Fig. 4a, blue fit). The predicted mass loss for the summation over these two fits is plotted in Fig. 4b (piecewise prediction in red) and displays the bend over or stifling trend of the corrosion rate, similar to that observed in the mass gain experiments (Fig. 1a).

The piecewise fit of the two modes displays a fit at shorter times that is comparable to full immersion trends but at longer times, the value for $b$ is nearly an order of magnitude lower, indicative of a corrosion rate approaching zero. ${ }^{33-35}$ This behavior can be explained by an increase in solution resistance and a decrease in the cathodic area across the electrolyte as it dries and corrosion products forms. Although corrosion products still build up on surfaces exposed in natural atmospheric environments, the drying rate associated with corrosion would be dependent on salt deposition rates and whether they exceed the drying rate. Provided constant salt deposition or higher initial salt load, the corrosion rate trend would be expected to move towards values comparable to those previously reported. ${ }^{33-35}$ This may be further supported by the finding that higher salt loadings, and in turn greater electrolyte volumes, resulted in longer times to stifling (2-3 times longer for samples with $125 \mu \mathrm{g} / \mathrm{cm}^{2}$ than the lower salt deposition exposures, Fig. 1a). In this manner, greater initial electrolyte volume may increase the time necessary for corrosion processes to reduce the total volume of electrolyte present, thus increasing the time to stifling.

The precipitation of carbonate phases resulting from the corrosion processes, primarily dawsonite $\left(\mathrm{NaAlCO}_{3}(\mathrm{OH})_{2}\right)$, are cause for the dramatic change in electrolyte volume. FTIR and GIXRD both indicate that dawsonite is the predominant corrosion product on the surface (Fig. 3). The formation of dawsonite leads to the reduction of electrolyte on the sample surface through the gettering of $\mathrm{Na}$.

Thermodynamic calculations using OLI analyzer of changes in water activity resultant from the expected corrosion processes predict considerable electrolyte volume shrinkage during corrosion. ${ }^{36}$ For example, stoichiometric replacement of $\mathrm{NaCl}$ with the corrosion product; $\mathrm{NaAlCO}_{3}(\mathrm{OH})_{2}$, resulted in reduction of the water volume by a factor of 100 . In the pitting environment, where hydrolyzed aluminum chlorides are expected to form, a reduction in droplet volume, although much less, would still be expected; for $\mathrm{Al}(\mathrm{OH})_{2} \mathrm{Cl}$ or $\mathrm{Al}_{2}(\mathrm{OH})_{5} \mathrm{Cl}$, the volume is reduced by a factor of 1.25 ; for $\mathrm{AlCl}_{3}$ this factor is 1.43 . It is important to note that in contrast to this volume conversion with dawsonite or the aluminum chlorides, the formation of aluminum hydroxide $\left(\mathrm{Al}(\mathrm{OH})_{3}\right)$ as a corrosion product, although not kinetically or thermodynamically favored to precipitate over dawsonite in the presence of excess carbonate and $\mathrm{Na}$ in solution, would not be expected to cause this large volume change. ${ }^{37}$ Sodium is not gettered in aluminum hydroxides and these corrosion products precipitate easily out of solution. Finally, the role of the aluminum hydroxycarbonate gel that forms is unclear as thermodynamic parameters were lacking to carry out this calculation. These are not expected to significantly getter $\mathrm{Na}$ nor $\mathrm{Cl}$ from solution, however, it has been suggested that chlorides could be incorporated into this gel. ${ }^{13}$

The experimental electrolyte volume reduction was calculated for the droplets from the in-situ initial and final images of the exposure (Fig. 2a). Contact angles and droplet diameters were used to estimate the initial volume. The final image displays the aluminum hydroxycarbonate gel on the surface, however, if this volume were electrolyte, the total remaining volume could be estimated from the height (in Fig. 2a) and the width and diameter of the spreading zone (from top down images not shown). This estimation resulted in an overall reduction in electrolyte volume by a factor of 15 . Although dawsonite formation has been 


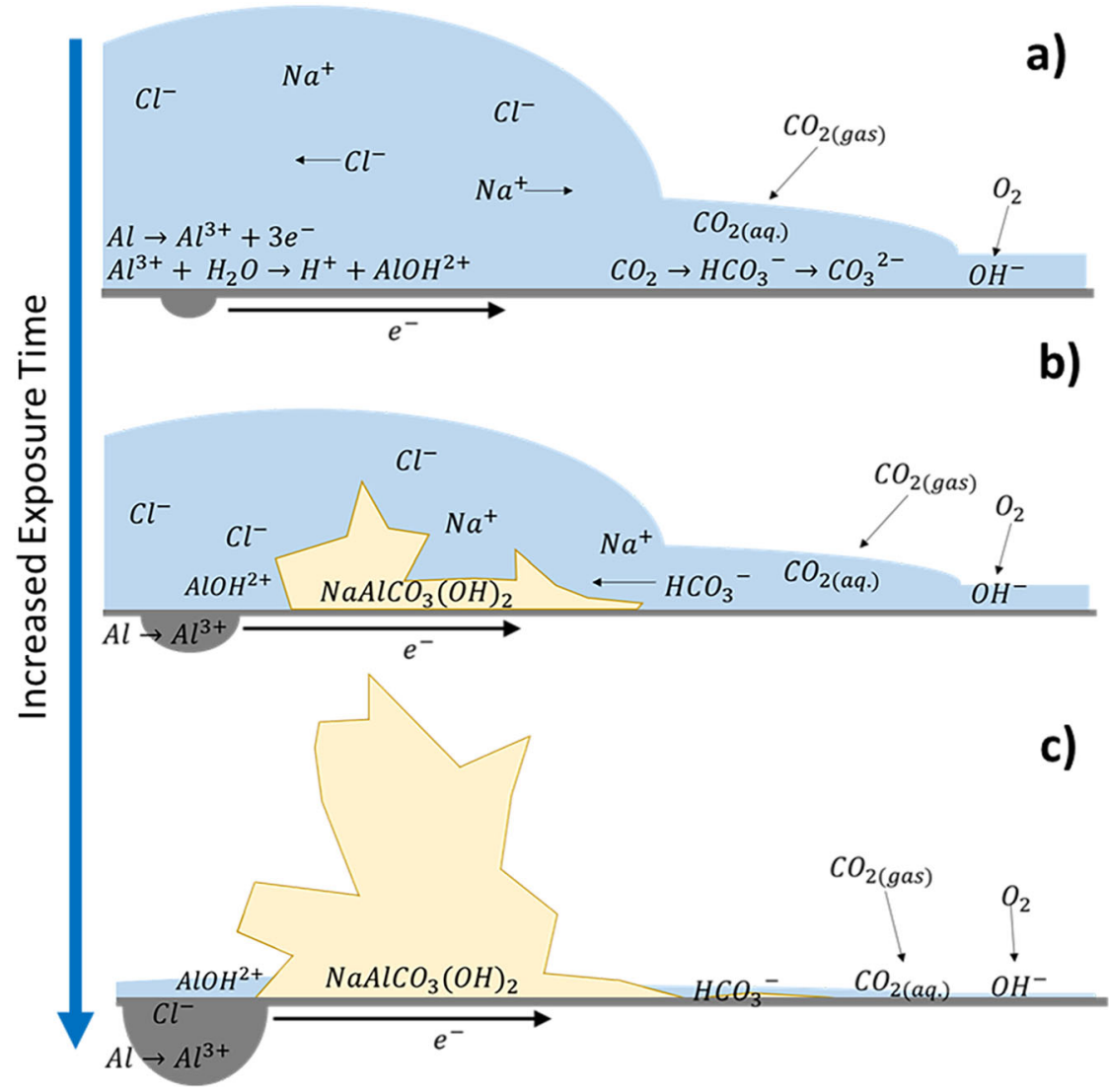

Fig. 5 Hypothetical schematic of corrosion processes in an $\mathrm{NaCl}$ droplet on Al over time; a initial establishment of pit, b growth of pit and corrosion product, and c growth of pit and corrosion product leading to electrolyte drying

previously reported for atmospheric exposures, it has not been considered as an integral part of the corrosion process. ${ }^{13,38}$

Thermodynamic calculations of corrosion products under atmospheric exposure conditions (e.g., $\mathrm{CO}_{2}$ ) demonstrate dawsonite as a predominant phase that should be considered in atmospheric corrosion of aluminum in saline environments. These calculations were made by allowing or suppressing the formation of aluminum hydroxides to represent cases of low and high levels of $\mathrm{Na}$ and $\mathrm{CO}_{2}$ in solution with respect to Al. First, a pit initiates and the chemical gradients (e.g., pH) are influenced by the corrosion processes (Fig. 5). At the pit, anodic dissolution occurs which leads to hydrolysis and acidification of this area, for example, via:

$\mathrm{Al}_{(\mathrm{s})} \leftrightarrow \mathrm{Al}^{3+}+3 e^{-}$

$\mathrm{Al}^{3+}+\mathrm{H}_{2} \mathrm{O} \leftrightarrow \mathrm{H}^{+}+\mathrm{AlOH}^{2+}$

$\mathrm{Al}^{3+}+2 \mathrm{H}_{2} \mathrm{O} \leftrightarrow 2 \mathrm{H}^{+}+\mathrm{Al}(\mathrm{OH})_{2}^{+}$

At $\mathrm{pH} 3$, representative of a pit environment, dawsonite is not the stable phase (Fig. 6a). Instead, aluminum chloride formation is favorable:

$\mathrm{Al}^{3+}+3 \mathrm{Cl}^{-}+6 \mathrm{H}_{2} \mathrm{O} \leftrightarrow \mathrm{AlCl}_{3} \cdot 6 \mathrm{H}_{2} \mathrm{O}_{(\mathrm{s})}+3 e^{-}$

It is also recognized that aluminum hydroxychlorides can form (e.g., $\left.\mathrm{Al}(\mathrm{OH})_{2} \mathrm{Cl}, \mathrm{Al}(\mathrm{OH}) \mathrm{Cl}_{2}\right)^{1,13}$ Their predominance, however, when evaluated in Eh-pH space from the database applied for Fig. 6, required the suppression of an aluminum oxyhydroxide solid, gibbsite $\left(\mathrm{Al}(\mathrm{OH})_{3}\right)$. In other words, this analysis suggests aluminum hydroxychlorides are not predominant in the conditions relevant to these experiments or that there are possible limitations with the thermodynamic data.

In the outer edges of the droplet, or regions more accessible to oxygen, the cathodic reaction (Eq. 7) occurs which can lead to higher $\mathrm{pH}$ regions.

$\mathrm{O}_{2(\mathrm{~g})}+4 \mathrm{e}^{-}+2 \mathrm{H}_{2} \mathrm{O} \leftrightarrow 4 \mathrm{OH}^{-}$

In these regions with easier access to the atmosphere, the presence of $\mathrm{CO}_{2}$ also has a significant influence on the solution chemistry.

$$
\begin{aligned}
& \mathrm{CO}_{2(\mathrm{~g})} \leftrightarrow \mathrm{CO}_{2(\mathrm{aq})} \\
& \mathrm{CO}_{2(\mathrm{aq})}+\mathrm{OH}^{-} \leftrightarrow \mathrm{HCO}_{3}^{-} \\
& \mathrm{HCO}_{3}^{-}+\mathrm{OH}^{-} \leftrightarrow \mathrm{CO}_{3}^{2-}+\mathrm{H}_{2} \mathrm{O}
\end{aligned}
$$

In the thermodynamic calculations, if the $\mathrm{pH}$ is increased slightly, to a $\mathrm{pH}=5$, representative of a location further up the pit or near the pit mouth, with the interaction of $\mathrm{CO}_{2}$, dawsonite can begin to precipitate (Eq. 11, Fig. 6b). When a high $\mathrm{pH}$ is considered, such as $\mathrm{pH}>7$, representative of the larger droplet volume and the droplet spreading zone, dawsonite is the thermodynamically favored phase (Eq. 12, Fig. 6c).

$$
\begin{aligned}
& \mathrm{AlOH}^{2+}+\mathrm{HCO}_{3}^{-}+\mathrm{Na}^{+}+\mathrm{H}_{2} \mathrm{O} \leftrightarrow \mathrm{NaAlCO}_{3}(\mathrm{OH})_{2(\mathrm{~s})}+2 \mathrm{H}^{+} \\
& \mathrm{Al}(\mathrm{OH})_{2}^{+}+\mathrm{HCO}_{3}^{-}+\mathrm{Na}^{+} \leftrightarrow \mathrm{NaAlCO}_{3}(\mathrm{OH})_{2(\mathrm{~s})}+\mathrm{H}^{+}
\end{aligned}
$$

Based on the experimental results and thermodynamic analyses, a new mechanism is proposed for atmospheric corrosion of aluminum that considers the formation of dawsonite resulting in electrolyte drying and corrosion rate stifling. With time, 

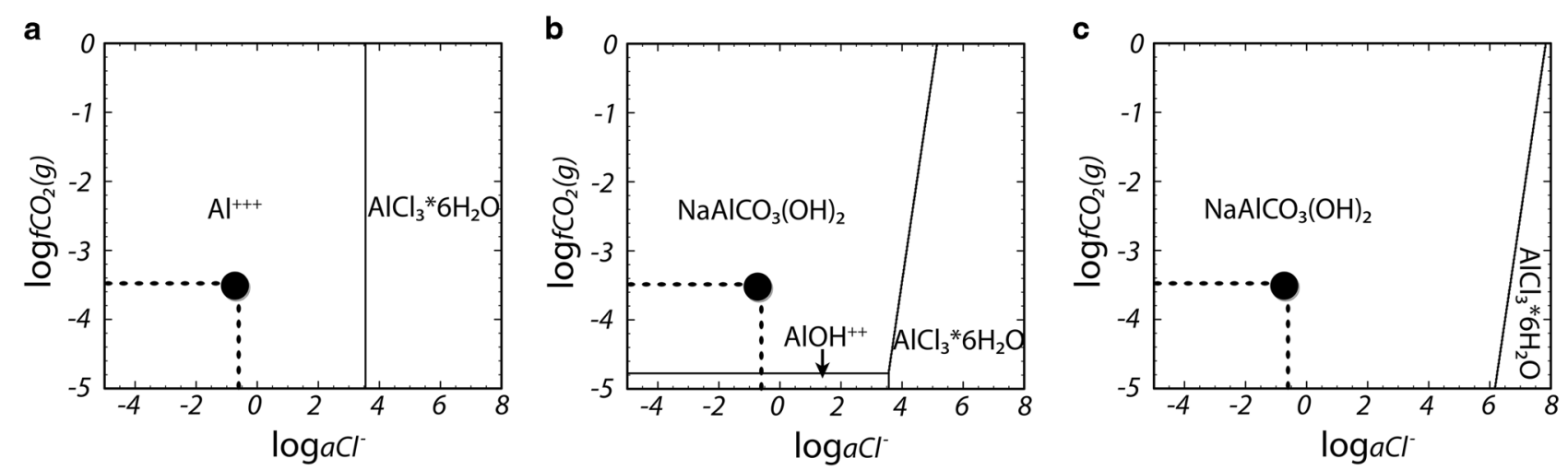

Fig. 6 Stability of expected phases in the aluminum - sodium chloride system for a range of $\mathrm{pH}$ vs. the chloride and carbonate activity. a pH $=3$ or lower, representative of an anodic acidic / chloride-rich pit environment, $\mathbf{b} \mathrm{pH}=5$, towards a more cathodic environment, and $\mathbf{c}$ increasing $\mathrm{pH} \geq 7$ representing a cathodic environment. The diagrams are constructed assuming the absence of gibbsite with an $\mathrm{Al}^{+++}$and $\mathrm{Na}^{+}$activities equal to $10^{-5}$ and 0.6 , respectively. Large dot denotes atmospheric exposure conditions

corrosion product precipitates, primarily in the form of dawsonite (Eq. 10), and finally, as this product builds up, the electrolyte within the system diminishes as $\mathrm{Na}$ is gettered, thus the corrosion rate is reduced and stifles. Here, dawsonite has been reported, and it has been demonstrated that the role of $\mathrm{CO}_{2}$ should be considered as significant in phase stability diagrams for atmospheric corrosion of aluminum unlike typical considerations for immersed systems.

This reaction pathway provides an alternative mechanism to those previously proposed and includes the influence of $\mathrm{CO}_{2}$ and the subsequent formation of dawsonite. While Blucher et al. observed the stagnation phenomena and related it to the presence of $\mathrm{CO}_{2}$ in the atmosphere, they proposed that $\mathrm{CO}_{2}$ neutralizes the $\mathrm{pH}$ of the cathodic region and thus inhibits corrosion at high $\mathrm{pH}$ as $\mathrm{Al}$ is amphoteric. ${ }^{25,38}$ However, there still remains a high chloride content within the electrolyte, and thus some corrosion would be expected to occur, even at a more neutral $\mathrm{pH}$. Therefore, $\mathrm{pH}$ neutralization alone could not fully account for the stagnation of the corrosion rate.

While $\mathrm{Na}$ is gettered in corrosion product, it is still not fully clear where or if the chloride is being consumed and the degree to which it is free or bound. The collocation of the chloride near the large corrosion product buildup and pitting attack, as seen in Fig. $2 b$, is expected as other studies of pitting in aluminum have noted high levels of chlorides in the pits. ${ }^{28}$ The presence of dawsonite post exposure has been previously identified by others on coupons exposed to atmospheric levels of $\mathrm{CO}_{2}$, whereas samples exposed without $\mathrm{CO}_{2}(<1 \mathrm{ppm})$ did not exhibit dawsonite, but rather a metal-corrosion product interface that was devoid of $\mathrm{Na}$ and only contained some $\mathrm{Cl}^{38}$ The corrosion product in that case was identified as bayerite $\left(\mathrm{a}-\mathrm{Al}(\mathrm{OH})_{3}\right)$ through XRD. ${ }^{38}$

Previous corrosion pathways ignored formation and presence of dawsonite, and described corrosion in $\mathrm{Al}$ as an autocatalytic phenomena, where $\mathrm{Cl}^{-}$is released at the cathode and migrates back to the anode, which would result in a continuous process. ${ }^{13}$ The results of this study and subsequent interpretation do not deny this reaction pathway, but indicate that the kinetics are greatly decelerated. Generally corrosion product on a surface can be considered as an ionic transport barrier. ${ }^{26}$ Dawsonite may also act in this manner thus further reducing the corrosion rates below the detection limits of the methods applied here. For a fully substantial understanding of the state of chloride in the system, whether free or bound, further work is still necessary. The results of this study, however, may be suggestive of chloride association with the dawsonite corrosion product as evidenced by the collocation of chloride with dawsonite in the EDS maps and the broadening of the FTIR bands from 3700 to 3200 (Figure 3). ${ }^{30,31}$
Under fixed salt loading conditions, atmospheric corrosion of aluminum can result in stifling due to the gettering of $\mathrm{Na}$ by dawsonite formation and subsequent reduction of electrolyte, thus controlling the extent and rate of corrosion. This reaction pathway provides a new perspective on atmospheric corrosion of aluminum which extends across many areas of atmospheric corrosion that assume constant electrolyte chemistries and geometries throughout the corrosion process. This includes the governance of chloride loading on corrosion rate, evaluation of the time of wetness, and corrosion modeling. As droplet morphology and electrolyte conditions are not constant or stable over time, measurement and modeling techniques need to account for this, especially if corrosion rate stifling occurs with electrolyte reduction due to corrosion product formation.

\section{METHODS}

\section{Materials}

Coupons of Al 1100, 99.0\% Aluminum (UNS A91100), $3.8 \mathrm{~cm}^{2}$, were ground to 1200 grit silicon carbide paper and polished with $1 \mu \mathrm{m}$ diamond paste. Coupons were cleaned with $18.2 \mathrm{M} \Omega$ deionized water and isopropyl alcohol, and dried in a compressed nitrogen stream prior to salt loading and exposure.

\section{Salt loading exposures}

Aluminum coupons were loaded on one side with 10,60 , or $125 \mu \mathrm{g} / \mathrm{cm}^{2}$ of $\mathrm{NaCl}$ particles using an inkjet printing method. ${ }^{39}$ After loading, samples were exposed in iso-humidity chambers at $98 \% \mathrm{RH}$ and $21^{\circ} \mathrm{C}$ for up to 672 h (1-28 days). Coupons were pulled at regular exposure intervals, dried and analyzed for mass gain, and returned to high humidity for exposure. Mass gain was performed using a calibrated microbalance with a repeatability of $\pm 10 \mu \mathrm{g}$. Three samples per exposure time were massed, a minimum of three times each, after drying in a nitrogen desiccator $(<10 \%$ $\mathrm{RH}$ ) for one hour. Drying was carried out to minimize the mass contribution of free water on the samples present during the $98 \% \mathrm{RH}$ exposure. Optical microscopy and GIXRD were carried out after exposure to characterize surface conditions. GIXRD was performed at a grazing angle of $0.5^{\circ}$ on a Siemens model D500 q-2q powder diffractometer (Bruker AXS, Inc. Madison, WI). Copper Ka $(0.15418 \mathrm{~nm})$ radiation was produced via a sealed-tube X-ray source and a diffracted-beam curved graphite monochromator; a conventional scintillation counter was used as the detector. Fixed $0.3^{\circ}$ incident beam and scatter slits were used (goniometer radius = $120 \mathrm{~mm}$ ), and the instrument power settings were $40 \mathrm{kV}$ and $30 \mathrm{~mA}$.

\section{In situ droplet exposures}

Droplets of $4 \mathrm{M} \mathrm{NaCl}$ were deposited on $\mathrm{Al} 1100$ coupons at $80 \% \mathrm{RH}$ using a capillary microinjection system. A minimum of ten droplets with average diameters of $200-250 \mu \mathrm{m}$ and initially spaced $250 \mu \mathrm{m}$ apart were deposited on each sample. Samples were moved to a smaller chamber, 
within 10 min of droplet loading, set at $98 \% \mathrm{RH}$ by an aqueous saturated $\mathrm{K}_{2} \mathrm{SO}_{4}$ solution and at $21^{\circ} \mathrm{C}$. An optical microscope was used to image the droplets in-situ during exposure, while temperature and humidity were recorded to ensure constant conditions.

Post exposure sample characterization was carried out using the methods described above for the salt printed experiments as well as scanning electron microscopy (SEM), energy dispersive spectroscopy (EDS), FTIR, and Raman spectroscopy. SEM was performed on a field emission Zeiss Supra 55VP and EDS was acquired using a Bruker quad, SDD detector and Esprit acquisition software with an accelerating voltage of $15 \mathrm{keV}$ and a working distance of $10 \mathrm{~mm}$. A Bruker Hyperion IR microscope was used for total reflection FTIR with $4 \mathrm{~cm}^{-1}$ resolution for corrosion product identification. For FTIR analysis, 512 co-added scans were taken in the range of $500-4000 \mathrm{~cm}^{-1}$, and referenced to Al 1100 as a background. Raman spectroscopy was conducted using a Witec Confocal Raman microscope with a $532 \mathrm{~nm}$ laser at $5 \mathrm{~mW}$, a 20x objective, and a theoretical resolution of $0.8 \mu \mathrm{m}$. Samples were cleaned using the ASTM G-1 procedure and imaged post cleaning using SWLI to determine the extent of corrosion damage. $^{40}$ Imaging was carried out on a Bruker Contour GTi Scanning White Light Interferometer operated at a magnification of $10 x$ with a $z$ resolution of $0.1 \mathrm{~nm}$ and a lateral resolution of $2 \mu \mathrm{m}$.

\section{Thermodynamic modeling}

Thermodynamic evaluation of equilibrium phase relations and construction of activity phase diagrams for the $\mathrm{Na}-\mathrm{Al}-\mathrm{CO}_{3}-\mathrm{H}_{2} \mathrm{O}$ system were conducted using the CHNOSZ software package developed for the $\mathrm{R}$ software environment. ${ }^{41}$ The thermodynamic data used with CHNOSZ is based on the work by Benezeth et al. for dawsonite, and Al metal and Al oxi-hydroxide solids from Robie and Hemingway, and Tutolo et al. ${ }^{42-44}$ Thermodynamic data for Al aqueous species are from Tagirov and Schott. ${ }^{45}$ Thermodynamic data for $\mathrm{AlCl}_{3} \cdot 6 \mathrm{H}_{2} \mathrm{O}$ solid along with binary Pitzer parameters for concentrated $\mathrm{AlCl}_{3}$ electrolyte were obtained from the work of Wang et al. ${ }^{46}$ Other Pitzer parameters relevant to this system were obtained from the thermodynamic database developed for salt precipitation in a subsurface nuclear waste repository (see Appendix I in Mariner). ${ }^{47}$

Construction of activity phase diagrams in Fig. 6 using CHNOSZ utilized the "mosaic" option to capture changes in topologic phase boundaries as a function of $\mathrm{Al}$ and $\mathrm{CO}_{2}$ aqueous speciation with $\mathrm{pH}$. The resulting phase topology is consistent with that described by Benezeth et al. for dawsonite equilibria with Al-hydroxides (gibbsite, boehmite). ${ }^{42}$ The effect of Alhydroxides was evaluated by allowing/suppressing these solids from the product phase assemblage. The effect of suppressing these solids is to represent the case where excess $\mathrm{Na}$ and $\mathrm{CO}_{2}$ (relative to $\mathrm{Al}$ ) in solution favors dawsonite formation (not shown) as suggested by Álvarez-Ayuso and Nugteren. ${ }^{37}$ Such observation is consistent with those in this study. The presence of an Al-hydroxide such as gibbsite $\left(\mathrm{Al}(\mathrm{OH})_{3}\right)$ was not detected in the experimental run products and its formation does not appear to be favored in $\mathrm{NaCl}$-bearing solutions buffered by $\mathrm{CO}_{2}$, as expected under atmospheric conditions. It should be noted that the activity phase diagrams depicted in Fig. 6 represent "snapshots" of chemographic relations constrained by fixed activities of $\mathrm{Al}$ and $\mathrm{Na}$ components. As corrosion progresses, changes in the aqueous concentrations of these components will also modify the relative stability fields and thus the saturation boundaries of the solids. Therefore, reaction path modeling with aqueous speciation and calculation of phase saturation is needed to evaluate these changes with the progression of corrosion reactions.

Equilibrium calculations between $\mathrm{Al}$ solids and aqueous solution along with reaction path modeling were conducted using the EQ3/6 software package (Wolery and Jarek). ${ }^{48}$ Reaction path simulations of Al metal interactions with aqueous phase were performed at $25^{\circ} \mathrm{C}$ and $1 \mathrm{bar}$ assuming a closed system with a 0.6 molal $\mathrm{NaCl}$ aqueous solution $\left(\mathrm{H}_{2} \mathrm{O}\right.$ activity of $\left.\sim 0.98\right)$ and a constant $\mathrm{CO}_{2(\mathrm{~g})}$ fugacity of 0.000316 bars (log $\left.f_{\mathrm{CO} 2(g)}=-3.5\right)$ to represent experimental conditions. The $\mathrm{CO}_{2(\mathrm{~g})}$ fugacity was varied in some cases to evaluate the effect of dissolved carbonate on dawsonite stability as a function of $\mathrm{pH}$. EQ3/6 simulations at low $\mathrm{pH}$ (pit environment) required using the Pitzer activity coefficient model to map $\mathrm{AlCl}_{3} \cdot 6 \mathrm{H}_{2} \mathrm{O}$ stability as a potential anodic phase. All other simulations at more dilute concentrations (i.e., $0.6 \mathrm{~m} \mathrm{NaCl}$ ) were conducted using the extended Debye-Hückel (b-dot) formulation in EQ3/6. Reaction path simulations at different initial $\mathrm{pH}$ values show the important effect of $\mathrm{CO}_{2}$ in maintaining the aqueous solutions within the near-neutral $\mathrm{pH}$ region with the addition of $\mathrm{Al}$ as corrosion progresses. It is within this near- neutral $\mathrm{pH}$ region where dawsonite is predominantly stable as delineated by the activity phase diagrams in Fig. 6 and reaction path modeling results.

Data availability

All relevant data are available from the authors of this manuscript.

\section{ACKNOWLEDGEMENTS}

The Authors gratefully acknowledge colleagues at Sandia National LaboratoriesBonnie McKenzie for SEM and EDS measurements and analysis, Alice Kilgo for metallographic sample preparation, Mark Rodriguez for GIXRD measurements, Laura Martin and Kathleen Alam for FTIR spectroscopy, and Brendan Nation for atmospheric corrosion cell design and fabrication.

\section{AUTHOR CONTRIBUTIONS}

R.S. and E.S. designed and discussed the study. R.S. and J.T. performed the atmospheric exposure experiments, and R.S. performed post exposure sample analysis. C.J. performed thermodynamic calculations and created the speciation diagrams. R.S. and E.S. discussed the results and R.S. wrote the manuscript with support from E.S. and C.J. All authors revised and approved the final manuscript Sandia National Laboratories is a multi-mission laboratory managed and operated by National Technology and Engineering Solutions of Sandia, LLC., a wholly owned subsidiary of Honeywell International, Inc., for the US Department of Energy's National Nuclear Security Administration under contract DE-NA0003525.

\section{ADDITIONAL INFORMATION}

Competing interests: The authors declare that they have no competing financial interests.

Publisher's note: Springer Nature remains neutral with regard to jurisdictional claims in published maps and institutional affiliations.

\section{REFERENCES}

1. Leygraf, C., Odnevall Wallinder, I., Tidblad, J. \& Graedel, T. E. Atmospheric corrosion 2nd edn (Wiley, Hoboken, NJ, 2016)

2. Elola, A. S., Otero, T. F. \& Porro, A. Evolution of the pitting of aluminum exposed to the atmosphere. Corrosion 48, 854-863 (1992).

3. Friel, J. J. Atmospheric corrosion products on $\mathrm{Al}, \mathrm{Zn}$, and Alzn metallic coatings. Corrosion 42, 422-426 (1986).

4. Sun, S. Q., Zheng, Q. F., Li, D. F. \& Wen, J. G. Long-term atmospheric corrosion behaviour of aluminium alloys 2024 and 7075 in urban, coastal and industrial environments. Corros. Sci. 51, 719-727 (2009).

5. Godard, H. P. The corrosion of light metals (Wiley, New York, 1967).

6. Mendoza, A. R. \& Corvo, F. Outdoor and indoor atmospheric corrosion of nonferrous metals. Corros. Sci. 42, 1123-1147 (2000).

7. Gonzalez, J. A., Morcillo, M., Escudero, E., Lopez, V. \& Otero, E. Atmospheric corrosion of bare and anodized aluminium in a wide range of environmental conditions. Part l: visual observations and gravimetric results. Surf. Coat. Technol. 153, 225-234 (2002)

8. Vera, R., Delgado, D. \& Rosales, B. M. Effect of atmospheric pollutants on the corrosion of high power electrical conductors: Part 1. Aluminium and AA6201 alloy. Corros. Sci. 48, 2882-2900 (2006).

9. Baker, E. A. in Degradation of Metals in the Atmosphere ASTM STP 965 (eds Dean, S.W. \& Lee, T.S.) 125-144 (ASTM International, Philadelphia, PA, 1988).

10. Li, S. J. et al. Evaluation of delayed fracture property of outdoor-exposed high strength AISI 4135 steels. Corros. Sci. 52, 3198-3204 (2010).

11. Townsend, H. E. Effects of alloying elements on the corrosion of steel in industrial atmospheres. Corrosion 57, 497-501 (2001).

12. Feliu, S., Morcillo, M. \& Chico, B. Effect of distance from sea on atmospheric corrosion rate. Corrosion 55, 883-891 (1999).

13. LeBozec, N., Jonsson, M. \& Thierry, D. Atmospheric corrosion of magnesium alloys: Influence of temperature, relative humidity, and chloride deposition. Corrosion 60, 356-361 (2004).

14. Ma, Y. T., Li, Y. \& Wang, F. H. The atmospheric corrosion kinetics of low carbon steel in a tropical marine environment. Corros. Sci. 52, 1796-1800 (2010).

15. de la Fuente, D., Diaz, I., Simancas, J., Chico, B. \& Morcillo, M. Long-term atmo spheric corrosion of mild steel. Corros. Sci. 53, 604-617 (2011).

16. Soares, C. G., Garbatov, Y., Zayed, A. \& Wang, G. Influence of environmental factors on corrosion of ship structures in marine atmosphere. Corros. Sci. 51, 2014-2026 (2009). 
17. Syed, S. Atmospheric corrosion of hot and cold rolled carbon steel under field exposure in Saudi Arabia. Corros. Sci. 50, 1779-1784 (2008).

18. Ambler, H. R. \& Bain, A. J. Corrosion of metals in the tropics. J. Chem. Technol. Biotechnol. 5, 437-467 (1955).

19. Roberge, P. R., Klassen, R. D. \& Haberecht, P. W. Atmospheric corrosivity modeling -a review. Mater. Des. 23, 321-330 (2002)

20. Chen, Z. Y., Cui, F. \& Kelly, R. G. Calculations of the cathodic current delivery capacity and stability of crevice corrosion under atmospheric environments. J. Electrochem. Soc. 155, C360-C368 (2008).

21. Chen, Z. Y. \& Kelly, R. G. Computational modeling of bounding conditions for pit size on stainless steel in atmospheric environments. J. Electrochem. Soc. 157, C69-C78 (2010).

22. Stratmann, M. \& Streckel, H. On the atmospheric corrosion of metals which are covered with thin electrolyte layers .2. Experimental results. Corros. Sci. 30, 697-714 (1990).

23. Nishikata, A., Ichihara, Y., Hayashi, Y. \& Tsuru, T. Influence of electrolyte layer thickness and $\mathrm{pH}$ on the initial stage of the atmospheric corrosion of iron. J. Electrochem. Soc. 144, 1244-1252 (1997).

24. Tsuru, T., Tamiya, K. I. \& Nishikata, A. Formation and growth of micro-droplets during the initial stage of atmospheric corrosion. Electrochim. Acta 49, 2709-2715 (2004).

25. Blucher, D. B., Lindstrom, R., Svensson, J. E. \& Johansson, L. G. The effect of CO2 on the $\mathrm{NaCl}$-induced atmospheric corrosion of aluminum. J. Electrochem. Soc. 148, B127-B131 (2001).

26. Dan, Z. H., Muto, I. \& Hara, N. Role of corrosion products in the suppression of atmospheric corrosion of aluminum and its alloys. ECS Trans. 25, 23-33 (2010).

27. Guseva, O., Schmutz, P., Suter, T. \& von Trzebiatowski, O. Modelling of anodic dissolution of pure aluminium in sodium chloride. Electrochim. Acta 54, 4514-4524 (2009).

28. Foley, R. T. \& Nguyen, T. H. The chemical nature of aluminum corrosion. 5. Energytransfer in aluminum dissolution. J. Electrochem. Soc. 129, 464-467 (1982).

29. Blucher, D. B., Svensson, J. E. \& Johansson, L. G. The NaCl-induced atmospheric corrosion of aluminum; the influence of carbon dioxide and temperature. J. Electrochem. Soc. 2001, 741-748 (2001).

30. Corazza, E., Sabelli, C., Vannucci, S. Dawsonite: new mineralogical data and structure refinement. Neues Jahrbuch fur Mineralogie 9, 381-397 (1977).

31. Serna, C. J., Garciaramos, J. V. \& Pena, M. J. Vibrational study of dawsonite type compounds $\mathrm{NaAl}(\mathrm{OH})_{2} \mathrm{CO}_{3}, \mathrm{KAI}(\mathrm{OH})_{2} \mathrm{CO}_{3}, \mathrm{NH}_{4} \mathrm{Al}(\mathrm{OH})_{2} \mathrm{CO}_{3}$. Spectrochim. Acta A 41, 697-702 (1985)

32. Lee, E. J. \& Pyun, S. I. The effect of oxide chemistry on the passivity of aluminum surfaces. Corros. Sci. 37, 157-168 (1995).

33. Hunkeler, F. \& Bohni, H. Determination of pit growth-rates on aluminum using a metal foil technique. Corrosion 37, 645-650 (1981).

34. Murer, N. \& Buchheit, R. G. Stochastic modeling of pitting corrosion in aluminum alloys. Corros. Sci. 69, 139-148 (2013).

35. Melchers, R. E. Time dependent development of aluminium Pitting Corrosion. Adv. Mater. Sci. Eng. (2015).

36. Wang, P. M., Anderko, A. \& Young, R. D. A speciation-based model for mixedsolvent electrolyte systems. Fluid Phase Equilib. 203, 141-176 (2002).

37. Alvarez-Ayuso, E. \& Nugteren, H. W. Synthesis of dawsonite: a method to treat the etching waste streams of the aluminium anodising industry. Water Res. 39, 2096-2104 (2005).
38. Blucher, D. B., Svensson, J. E. \& Johansson, L. G. The influence of $\mathrm{CO}_{2}, \mathrm{ACl}_{3} \cdot 6 \mathrm{H}_{2} \mathrm{O}$, $\mathrm{MgCl}_{2} \cdot 6 \mathrm{H}_{2} \mathrm{O}, \mathrm{Na}_{2} \mathrm{SO}_{4}$ and $\mathrm{NaCl}$ on the atmospheric corrosion of aluminum. Corros. Sci. 48, 1848-1866 (2006).

39. Schindelholz, E. \& Kelly, R. G. Application of Inkjet printing for depositing salt prior to atmospheric corrosion testing. Electrochem Solid State Lett. 13, C29-C31 (2010).

40. ASTM Standard G1-03. Standard practice for preparing, cleaning, and evaluating corrosion test specimens. (ASTM International, West Conshohocken, PA, 2011).

41. Dick, J. M. Calculation of the relative metastabilities of proteins using the CHNOSZ software package. Geochem. Trans. 9, 10 (2008).

42. Benezeth, P., Palmer, D. A., Anovitz, L. M. \& Horita, J. Dawsonite synthesis and reevaluation of its thermodynamic properties from solubility measurements: implications for mineral trapping of $\mathrm{CO}(2)$. Geochim. Cosmochim. Acta 71, 4438-4455 (2007).

43. Robie, R. A., Hemingway, B. S. Thermodynamic properties of minerals and related substances at $298.15 \mathrm{~K}$ and 1 bar $\left(10^{5}\right.$ pascals) pressure and at higher temperatures. US Geol. Survey Bull., 2131, 461 (1995).

44. Tutolo, B. M., Kong, X. Z., Seyfried, W. E. \& Saar, M. O. Internal consistency in aqueous geochemical data revisited: applications to the aluminum system. Geochim. Cosmochim. Acta 133, 216-234 (2014).

45. Tagirov, B. \& Schott, J. Aluminum speciation in crustal fluids revisited. Geochim. Cosmochim. Acta 65, 3965-3992 (2001).

46. Wang, J. F., Petit, C., Zhang, X. P. \& Cui, S. A. Phase equilibrium study of the AICl3$\mathrm{CaCl} 2-\mathrm{H} 2 \mathrm{O}$ system for the production of aluminum chloride hexahydrate from Ca-rich flue ash. J. Chem. Eng. Data 61, 359-369 (2016).

47. Mariner, P. In-Drift Precipitates/salts Model. ANL-EBS-MD-000045 Rev.02. November 2004. Prepared for: U.S. Department of Energy Office of Civilian Radioactive Waste Management, Office of Repository Development 1551, Hillshire Drive, Las Vegas, Nevada 89134-6321. Prepared by: Bechtel SAIC Company, LLC, 1180 Town Center Drive, Las Vegas, Nevada 89144. Contract Number DE-AC28$01 \mathrm{RW} 12101$.

48. Wolery, T. J., Jarek, R. L. EQ3/6, Version 8.0: Software User's Manual, 2003. Vol. 10813-UM-8. 0-00 (ed. Sandia National Laboratories) 376 (US Department of Energy, Office of Civilian RadioactiveWaste Management, Albuquerque, NM, 2003)

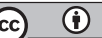

Open Access This article is licensed under a Creative Commons Attribution 4.0 International License, which permits use, sharing, adaptation, distribution and reproduction in any medium or format, as long as you give appropriate credit to the original author(s) and the source, provide a link to the Creative Commons license, and indicate if changes were made. The images or other third party material in this article are included in the article's Creative Commons license, unless indicated otherwise in a credit line to the material. If material is not included in the article's Creative Commons license and your intended use is not permitted by statutory regulation or exceeds the permitted use, you will need to obtain permission directly from the copyright holder. To view a copy of this license, visit http://creativecommons. org/licenses/by/4.0/.

(c) The Author(s) 2017 